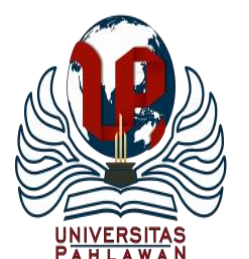

Jurnal Abdidas Volume 2 Nomor 1 Tahun 2021 Halaman 86-91

JURNAL ABDIDAS

http://abdidas.org/index.php/abdidas

\title{
Pemberdayaan Potensi Desa Kebon Raya Paciran Lamongan di Era New Normal
}

\author{
Mochamad Mochklas $^{1 \bowtie}$, Sjamsul Hidajat $^{2}$, Nurullaili Mauliddah ${ }^{3}$ \\ Program Studi Manajemen, Fakultas Ekonomi dan Bisnis, Universitas Muhammadiyah Surabaya, Indonesia ${ }^{1,3}$ \\ Program Studi Akuntansi, Fakultas Ekonomi dan Bisnis, Universitas Muhammadiyah Surabaya, Indonesia ${ }^{2}$ \\ E-mail : mmochklas@fe.um-surabaya.ac.id ${ }^{1}$ sjamsulmiqot@gmail.com $^{2}$ nurullaili-mauliddah@ $@$ fe.um- $^{3}$ \\ surabaya.ac.id $^{3}$
}

\begin{abstract}
Abstrak
Kebon Raya salah satu di desa Paciran yang jumlah penduduk tidak terlalu banyak dibandingkan desa lainnya yang mata pencarian warga desa Kebon Raya sebagai petani memiliki sumber daya tanaman siwalan. Pendampingan di desa Kebon Raya bertujuan untuk meningkatkan pendapatan masyarakat desa dengan mengembangkan potensi yang ada, yaitu tanaman siwalan. Dengan mengunakan pendekatan partisipatif masyarakat kegiatan ini memperdayakan potensi tanaman dengan membuat gula aren bubuk dan stik siwalan. Diambilnya gula aren bubuk dan stik siwalan sebagai disertifikasi usaha masyarakat desa Kebon Raya, karena mudah pembuatannya tidak membutuhkan teknologi tinggi. Agar kegiatan pengabdian masyarakat efektif mahasiswa dilibatkan dalam pendampingan dan pelatihan usaha pembuatan gula aren bubuk dan stik siwalan. Untuk terus memotivasi dan keterikatan secara emosional masyarakat terhadap kegiatan ini pasca kegiatan pendampingan pemberdayaan evaluasi dan monitoring baik secara offline maupun online.
\end{abstract}

Kata kunci: siwalan, gula bubuk aren, stick siwalan, desa Kebon Raya

\begin{abstract}
Kebon Raya is one of the villages in Paciran village where the population is not too much compared to other villages where the livelihood of Kebon Raya villagers as farmers has the resources of siwalan plants. Assistance in the village of Kebon Raya aims to increase the income of the village community by developing the existing potential, namely the siwalan plant. By using a community participatory approach, this activity empowers the potential of the plant by making powdered palm sugar and palm sticks. He took the powdered palm sugar and siwalan sticks as a certificate of the business of the Kebon Raya village community, because it was easy to manufacture and did not require high technology. In order for community service activities to be effective, students are involved in mentoring and training in making powdered palm sugar and siwalan sticks. To continue to motivate and emotionally attach the community to this activity after the evaluation and monitoring empowerment assistance activities both offline and online.
\end{abstract}

Keywords: siwalan, palm powdered sugar, siwalan sticks, Kebon Raya village

Copyright (c) 2021 Mochamad Mochklas, Sjamsul Hidajat, Nurullaili Mauliddah

$\triangle$ Corresponding author

Address : Universitas Muhammadiyah Surabaya

Email : mmochklas@fe.um-surabaya.ac.id

DOI $\quad:$ https://doi.org/10.31004/abdidas.v2i1.219

ISSN 2721- 9224 (Media Cetak)

ISSN 2721- 9216 (Media Online) 


\section{PENDAHULUAN}

Kecamatan Paciran merupakan salah satu kecamatan yang ada di wilayah Kabupaten Lamongan yang berada di belahan utara ibu kota Kabupaten Lamongan dengan jarak $+43 \mathrm{Km}$ yang terdiri dari 16 desa 1 kelurahan, 34 dusun, 95 RW, 379 RT. Luas wilayah Kecamatan Paciran 61,304 $\mathrm{Km}^{2}$ terletak pada ketinggian $2 \mathrm{~m}$ di atas permukaan air laut. Desa Paciran merupakan salah satu desa yang ada di kecamatan Paciran Lamongan dimana terdapat objek wisata yang sangat terkenal yaitu Wisata Bahari Lamongan (Kecamatan Paciran).

Kebon Raya merupakan salah satu di desa di Paciran yang jumlah penduduk tidak terlalu banyak dibandingkan desa lainnya di Desa Paciran, dimana mata pencarian warga sebagai petani. Kondisi alam Kebon Raya memungkin tumbuh pohon siwalan karena lahan di desa ini termasuk dilahan kritis. Tanaman siwalan sangat ideal tumbuh di dataran kering dan terbuka, dengan ketinggian 0-500 mdpl (Husaini et al., 2020). Tanaman siwalan menjadi salah satu potensi yang dapat dikembangkan dalam meningkatkan pendapat masyarakat desa Kebon Raya.

Siwalan merupakan pohon palma yang mirip aren dan kelapa namun memiliki buah berbeda (Mojiono \& Mubarok, 2019). Buah siwalan berbentuk bulat dengan daging buah yang lembut. Pohon ini biasa tumbuh di daerah pesisir yang kering (Sustiyana et al., 2013). Buah siwalan bukan hanya memiliki rasa yang nikmat tetapi juga memiliki kandungan gizi yang tinggi, sehingga mengkonsumsi buah siwalan tentunya akan sangat baik bagi tubuh (Krisnawati et al., 2019).

Siwalan merupakan komoditas pertanian yang unik dan unggul, sejauh ini masyarakat memanfaatkan siwalan untuk komoditas perdagangan dengan cara konvensional (Apriyanti, 2018). Selian bertani warga desa Kebon Raya, memanfaatkan tanaman siwalan sebagai tambahan pemasukan keuangan keluarga. Di desa ini oleh masyarakat pohon siwalan dijual sebagai minuman legen, gula aren dan buah. Legen merupakan air nira yang keluar dari pohon Siwalan melalui tangkai tandan bunga yang dipotong kemudian disadap. Akan tetapi, legen cepat sekali basi. Kesegarannya hanya bisa bertahan satu hari. Lebih dari itu, legen mengalami fermentasi, rasanya jadi kecut. Kandungan gula pada legen berubah menjadi cuka dan alkohol. Makin lama terfermentasi, makin tinggi kandungan alkoholnya. Dalam bahasa setempat, legen yang telah basi disebut tuak, karena mengandung banyak alkohol.

Masyarakat perlu didorong berwirausaha sesuai dengan karakteristiknya. Menurut Purwanti (2012) bahwa karakteristik wirausaha berpengaruh terhadap perkembangan usaha. Karakteristik masyarakat di desa Kebon Raya adalah pohon siwalan, maka perlu pengembangan siwalan sebagai produk yang dapat dikembangkan di desa ini. Pendampingan Perguruan Tinggi dalam pemberdayaan masyarakat, diharapkan dapat terciptanya kemandirian masyarakat (Mochklas, et al, 2019). Aspek pengabdian tidak kalah pentingnya dengan aspek pedidikan dan penelitian, aspek pengabdian merupakan kunci atau parameter berhasil atau tidaknya bagi Perguruan Tinggi 
dalam menyelenggarakan pendidikan (Suryana, 2018).

\section{METODE}

Kegiatan pengabdian pada masyarakat di desa Kebon Raya Paciran Lamongan bertujuan untuk menggali potensi masyarakat Kebon Raya untuk meningkatkan pendapatan masyarakat, dengan menggali potensi masyarakat desa Kebon Raya Paciran diversifikasi usaha yang telah ada di masyarkat desa Kebon Raya Paciran.

Metode pelaksanaan pengabdian masyarakat di desa Kebon Raya mengunakan pendekatan partisipatif masyarakat dengan melakukan pendampingan digunakan metode diskusi dan pelatihan. Supervisi dan pemantauan di lakukan untuk melihat perkembangan dari pendampingan dan pelatihan yang telah dilakukan.

Kegiatan pengabdian masyarakat yang dilakukan ini melibatkan mahasiswa dalam pendampingan dan pelatiahan usaha. Sebelum pelaksanaan kegiatan pengabdian di desa Kebon Raya Paciran dilakukan beberapa tahapan, yaitu:

- Pertemuan dengan warga desa Kebon Raya untuk menggali potensi masyarakat desa Kebon Raya.

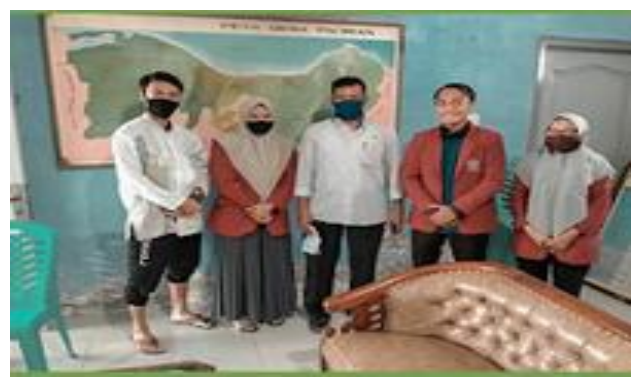

Gambar 1a. Tim Diskusi dengan Kepala Desa Paciran
- Melakukan analisa potensi masyarkat yang bisa dikembangkan.

- Melakukan diskusi dengan warga desa Kobon Raya Paciran hasil analisa potensi masyarakat.

- Melakukan koordinasi dengan warga, terkait dengan jadwal kegiatan pendampingan.

\section{HASIL DAN PEMBAHASAN}

Dari analisa lapangan yang telah dilakukan oleh tim pengabdian bahwa:

a) Potensi desa Kebon Raya adalah banyaknya tanaman siwalan.

b) Pada musim kemarau produktifitas air nira pohon siwalan lebih banyak ketimbang musim hujan.

c) Siwalan oleh warga atau petani di desa ini hanya dijual air nira, legen atau buah siwalan sehingga secara ekonomis sangat kurang.

Dari analisa lapangan tersebut disepakati dengan antara pendamping dengan warga untuk membuat gula aren bubuk dan stik siwalan. Diambilnya gula aren bubuk dan stick siwalan sebagai disertifikasi usaha masyarakat desa Kebon Raya, karena mudah pembuatannya tidak membutuhkan teknologi tinggi.

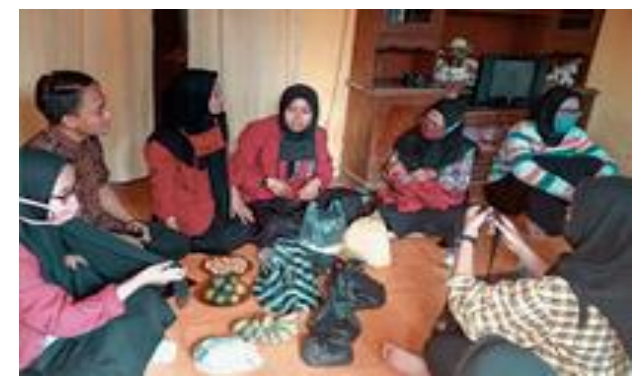

Gambar 1b. Sosialisasi Kegiatan di Desa Kebon Raya Paciran 
Agar para masayarakat dapat membuat produk tersebut diberi pelatihan, dimana materi pelatihan adalah meningkatkan potensi sumber daya yang ada di desa Kebon Raya Paciran dan dan diversifikasi produk. Dalam pelatihan ini warga diajarkan bagaimana meningkatkan kualitas dan kuantitas hasil produksi olahan berbahan siwalan. Dengan membuat inovasi makan berbahan siwalan yang mempunyai variasi rasa dan bentuk yang lebih menarik dan memiliki kekhasan tersendiri, serta bagaimana meningkatkan kualitas dan kuantitas hasil produksi.

Untuk efektifitas pendampingan media yang digunakan dalam pelatihan ini melalui diskusi, tutorial dan praktek produksi membuat gula bubuk aren dan stik siwalan dan pelatihan packing membuat logo sebuah produk agar lebih menarik serta memiliki daya jual.

\section{a. Pelatihan Pembuatan Gula Aren Bubuk}

Cara pembuatan gula aren bubuk, air nira dimasukan kedalam kuali di atas tungku, diaduk secara berkala dan manual kurang lebih selama 3 jam pemasakan adonan tidak boleh ditinggalkan terlalu lama dan api juga harus dijaga. Sebab kalau kurang aduk atau api terlalu besar ada kemungkinan gula di dasar wajan hangus. Setelah mengkristal adonan dikeringkan denga dijemur dibawah terik matahari.
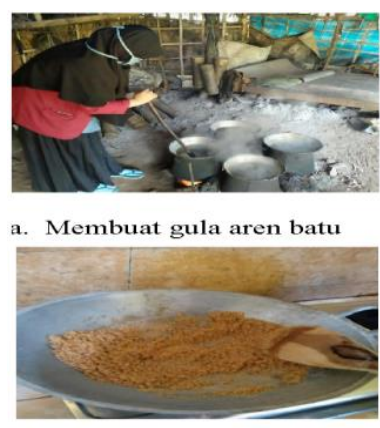

d. Gula aren bubuk

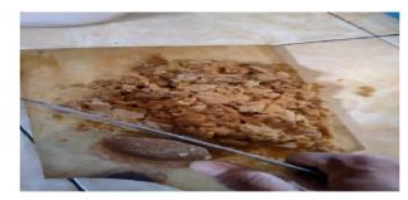

b. Potong tipis-tipis gula batu

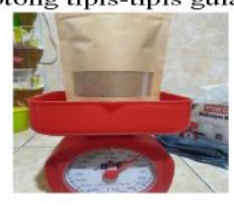

e. Packing

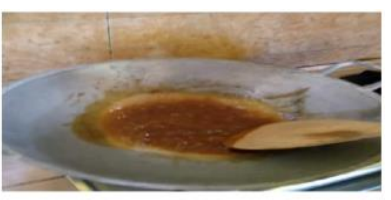

c. Sangrai gula batu aren

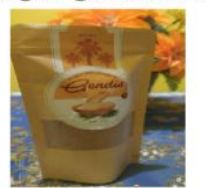

f. Produk Gula Aren Bubuk

Gambar 2. Pelatihan Pembuatan Gula Bubuk Aren

\section{b. Pelatihan Pembuatan Stick Siwalan}

Pembuatan stick siwalan sangat sederhan dan tidak memerlukan waktu yang lama, dan rasa stick siwalan bisa dikreasikan berbagai rasa, mulai dari asin, manis, hingga pedas tanpa mengurasi cita rasa siwalan itu sendiri.

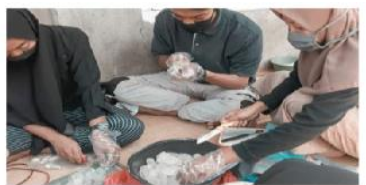

a. Mengelupas buah siwalan

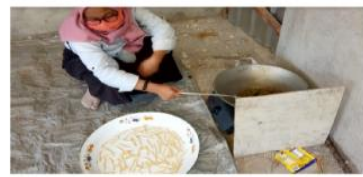

d. Menggoreng Stik Siwalan

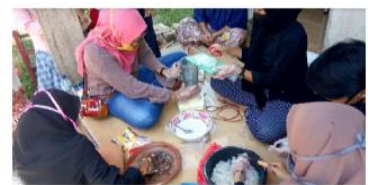

b. Membuat adonan

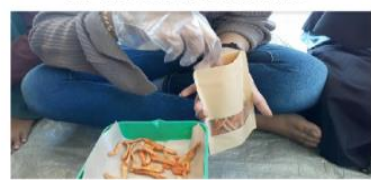

e. Packing

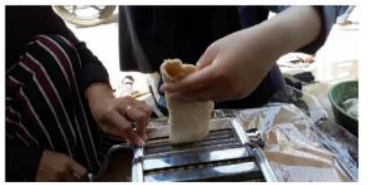

c. Menghaluskan adonan

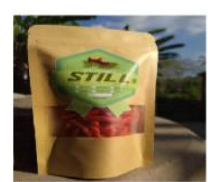

f. Produk Stik Siwalan

Gambar 3. Pelatihan Pembuatan Stik Siwalan 


\section{c. Pelatihan pemasaran}

Produk gula aren bubuk dan stik siwalan dikemas dengan menggunakan standing pouch, tujuannya agar produk-produk ini dapat beda dengan produklainnya sehingga dapat menembus minimarket dan juga supermarket yang ada, selain itu juga dengan kemasan yang baru juga bentuk gula yang bubuk, produk ini bisa dipasarkan secar online ke seluruh Indonesia. Produk gula jawa bubuk ini diberi nama "Gendis", dan stik buah siwalan ini sendiri diberi nama "STILL" singkatan dari Stik Siwalan Legit.

Agar produk gula aren bubuk dan siwalan dapat meningkat penjualan warga masyarakat juga diberi latihan pemasaran baik secara tradisonal atau konvensional juga pemasaran secara online. Dalam pelatihan pemasaran secara online warga diberi pelatihan cara upload gambar produk, serta memberi diskripsi agar konsumen tertarik untuk membeli.

\section{d. Pemantau kegiatan}

Evaluasi dan monitoring pasca kegiatan pendampingan pemberdayaan potensi masyarakat desa Kobon Raya, dilakukan secara optimal agar dapat memberikan motivasi dan keterikatan secara emosional sehingga masyarakat tetap bisa menjalankan usaha ini secara maksimal.

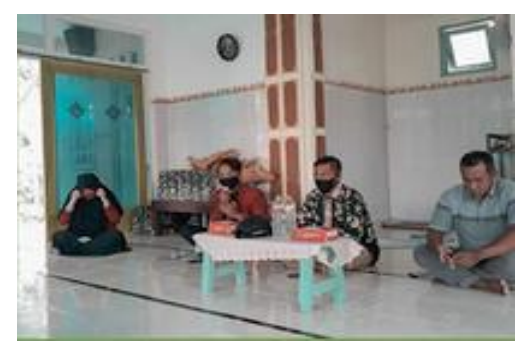

Gambar 4a. Rapat Evaluasi Kegiatan secara Offline
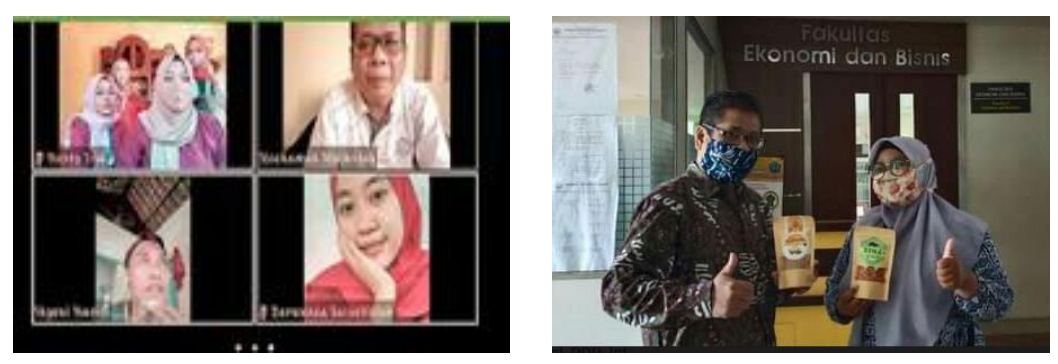

Gambar 4b. Rapat Evaluasi Gambar 4c. Laporan Kegiatan Kegiatan secara Online

\section{SIMPULAN}

Karakteristik desa Kebon Raya yang memiliki sumber daya tanaman siwalan perlu dikembangkan, karakteriktik masyarakat berpengaruh terhadap minat meningkatkan usaha yang ada. Lokasi desa yang dekat dengan tempat wisata di paciran gula bubuk aren dan stik siwalan merupakan usahan yang dapat dikembangkan di desa ini.
Diambilnya gula aren bubuk dan stik siwalan sebagai disertifikasi usaha masyarakat desa Kebon Raya, karena mudah pembuatannya tidak membutuhkan teknologi tinggi. Agar kegiatan pengabdian masyarakat efektif mahasiswa dilibatkan dalam pendampingan dan pelatihan usaha pembuatan gula aren bubuk dan stik siwalan. Untuk terus memotivasi dan keterikatan secara emosional masyarakat terhadap kegiatan ini pasca kegiatan pendampingan 
Pemberdayaan Potensi Desa Kebon Raya Paciran Lamongan di Era New Normal - Mochamad Mochklas, Sjamsul Hidajat, Nurullaili Mauliddah

DOI: https://doi.org/10.31004/abdidas.v2i1.219

pemberdayaan evaluasi dan monitoring baik secara offline maupun online.

\section{UCAPAN TERIMA KASIH}

Kami sampaikan banyak terimakasih kepada Kepala LPPM Universitas Muhammadiyah Surabaya yang memberikan dukungan kegiatan ini, dan kepada mahasiswa Universitas Muhammadiyah Surabaya yang terlibat pengabdian di desa Kebon Raya Paciran kegiatan ini Ihyaul Haqiqi, Elif Hidayah, Muhammad Atif Sidqi, Yuli Maulidiyah, Azlin Halizah, Rizkia Hani Prahastutik, Veny Safitri, Syahrian Lucky Anugrah, Alfullaily, Dyna Afitri, Zarwadah Salsabillah, Seb Nofem Siti Achirotin, Wardatul 'Izzah, Heppy Tria Mar'atun Ni'mas, Fifi Anggi Lestari, Elok Azifatul Izza, Nur Indah Rahmadhany.

\section{DAFTAR PUSTAKA}

Apriyanti, I. R. (2018). Studi Potensi Pemanfaatan Limbah Serat Batok Siwalan (Borassus Flabellifer L.) Sebagai Bahan Baku Kerajinan Lokal (Benang) Gresik. Jurnal Teknologia, 1(1), 79-86. Https://Aperti.EJournal.Id/Teknologia/Article/View/10

Husaini, F., Respati, S. M. B., \& Dzulfikar, M. (2020). Pengaruh Variasi Fraksi Volume Dan Arah Serat Pada Komposit Matrik Resin Polyester Berpenguat Serat Pelepah Lontar (Borassus Flabellifer) Dengan Perlakuan Naoh 5\% Terhadap Kekuatan Uji Tarik. Jurnal Ilmiah Momentum. https://Doi.Org/10.36499/Mim.V16i1.3349

Kamase, J. \& St. Sukmawati, S. (2019). Pelatihan Pembuatan Pembuatan Produk Stick Siwalan. Jurnal Pengabdian Bina Ukhuwah, 1(2): 47-53.

Kecamatan Paciran. https://lamongankab.go.id/paciran/profil
Krisnawati, I., Jazimatul, Agus, M., \& Dhini, S. (2019). J-Lan (Jelly Siwalan Khas Tuban) Kekayan Lokal Bumi Wali. Prosiding Seminar Nasional, 4(1), 58-62. Http://Prosiding.Unirow.Ac.Id/Index.Php/Sn asppm/Article/View/282

Mochklas, M., Rusmawati, Z., Santoso, A., \& Jannah, R. (2019). Pendampingan kampung pendidikan kampung'e arek Suroboyo (KP KAS) RW 03 Kelurahan Ketintang Surabay. Jurnal Komunitas: Jurnal Pengabdian kepada Masyarakat, 2(1), 51-59.

Mojiono \& Mubarok, W. N. (2019). Fresh-Cut Siwalan: Upaya Peningkatan Nilai Tambah Siwalan Sebagai Komoditas Unggulan Desa Murtajih, Kabupaten Pamekasan. Seminar Nasional Hasil Pengabdian Kepada Masyarakat (SENIAS) (pp. 1-4). Madura: Universitas Islam Madura.

Purwanti, E. (2012). Pengaruh Karakteristik Wirausaha, Modal Usaha, Strategi Pemasaran Terhadap Perkembangan Umkm Di Desa Dayaan Dan Kalilondo Salatiga. Among Makarti, 5(9), 13-28

Suryana, S. (2018). Peran Perguruan Tinggi Dalam Pemberdayaan Masyarakat. Jurnal Pendidikan Islam Rabbani, 2(2); 368-378.

Sustiyana, Syafrial, \& Purnomo, M. (2013). Analisis Supply Chain Dan Efisiensi Pemasaran Gula Siwalan (Studi Kasus Di Kecamatan Dungkek, Kabupaten Sumenep). Habitat, 24(2), 110-119. 